\title{
Registered report: Fusobacterium nucleatum infection is prevalent in human colorectal carcinoma
}

\section{John Repass ${ }^{1}$, Nimet Maherali ${ }^{2}$, Kate Owen ${ }^{3}$, Reproducibility Project: Cancer Biology*}

\author{
${ }^{1}$ ARQ Genetics, Bastrop, United States; ${ }^{2}$ Harvard Stem Cell Institute, Cambridge, \\ United States; ${ }^{3}$ University of Virginia, Charlottesville, United States
}

REPRODUCIBILITY CANCER BIOLOGY

*For correspondence: nicole@ scienceexchange.com

Group author details: Reproducibility Project: Cancer Biology See page 8

Competing interest: See page 8

Funding: See page 8

Received: 13 July 2015

Accepted: 30 November 2015

Published: 11 February 2016

Reviewing editor: Cynthia L Sears, Johns Hopkins University School of Medicine, United States

(c) Copyright Repass et al. This article is distributed under the terms of the Creative Commons Attribution License, which permits unrestricted use and redistribution provided that the original author and source are credited.
Abstract The Reproducibility Project: Cancer Biology seeks to address growing concerns about reproducibility in scientific research by conducting replications of selected experiments from a number of high-profile papers in the field of cancer biology. The papers, which were published between 2010 and 2012, were selected on the basis of citations and Altmetric scores (Errington et al., 2014). This Registered Report describes the proposed replication plan of key experiments from 'Fusobacterium nucleatum infection is prevalent in human colorectal carcinoma' by Castellarin and colleagues published in Genome Research in 2012 (Castellarin et al., 2012). The experiment to be replicated is reported in Figure 2. Here, Castellarin and colleagues performed a metagenomic analysis of colorectal carcinoma (CRC) to identify potential associations between inflammatory microorganisms and gastrointestinal cancers. They conducted quantitative real-time PCR on genomic DNA isolated from tumor and matched normal biopsies from a patient cohort and found that the overall abundance of Fusobacterium was 415 times greater in CRC versus adjacent normal tissue. These results confirmed earlier studies and provide evidence for a link between tissue-associated bacteria and tumorigenesis. The Reproducibility Project: Cancer Biology is a collaboration between the Center for Open Science and Science Exchange and the results of the replications will be published in eLife.

DOI: 10.7554/eLife.10012.001

\section{Introduction}

The human intestine is populated by an estimated $10^{14}$ microbes comprising over 1000 bacterial phylotypes (Ley et al., 2006). The overall composition of the intestinal microbiota is determined by a number of factors, including host genetics, environment, diet and hygiene (Arrieta et al., 2014; Keku et al., 2015). These bacteria play important roles in host biology by maintaining intestinal homeostasis, barrier function, immunity and metabolic function (Backhed et al., 2005; Jones et al., 2014). Perturbations or imbalances in the microbiome (microbial dysbiosis) are linked to a number of disease pathologies such as inflammatory bowel disease (Collins, 2014; Hold et al., 2014), obesity (Bajzer and Seeley, 2006; Brown et al., 2012), and colorectal cancers (CRCs; Dulal and Keku, 2014; Keku et al., 2015).

CRC is a complex disease arising from the sequential accumulation of somatic mutations and epigenetic alterations. Activating mutations in the K-ras oncogene, as well as the loss of tumor suppressor genes like p53 (TP53) and adenomatous polyposis coli (APC), contribute to the tumorigenic transformation of normal colonic epithelium (Vogelstein et al., 1988; Fearon, 2011; Mundade et al., 2014). In addition to genetic factors, microbial dysbiosis, such as altered bacterial diversity, is strongly associated with the development of CRC (Keku et al., 2015). However, despite numerous longitudinal studies comparing intestinal microbial communities over time 
(Rodriguez et al., 2015), and across various cancer stages (Kubota, 1990; Chen et al., 2013; Nugent et al., 2014), there is limited information on the contribution of specific bacteria to CRC development.

To identify potential associations between inflammatory microorganisms and gastrointestinal cancers, Castellarin et al. (2012) first performed RNA sequencing (RNA-seq) on a limited number of tumor and matched normal tissue samples. Initial observations indicated a striking overrepresentation of Fusobacterium nucleatum sequences in carcinoma samples compared to controls. To confirm these findings, Castellarin et al. (2012) assessed the relative abundance of Fusobacterium in a larger cohort of tumor and matched normal biopsy samples. In Figure 2, the authors performed quantitative real-time PCR (qPCR) on genomic DNA (gDNA) isolated from an additional 88 colorectal carcinoma (CRC) specimens and adjacent matched control tissues. Fusobacterium abundance was observed to be significantly higher in the tumor samples compared to matching control samples. This key experiment will be replicated in Protocol 1.

Similar findings confirming the higher relative abundance of Fusobacterium in CRC tumor tissues compared to control biopsies have been reported by other investigators (Kostic et al., 2012; McCoy et al., 2013; Warren et al., 2013; Tahara et al., 2014). In fact, the study by Kostic et al. (2012) is considered a co-discovery of this phenomenon. McCoy et al. (2013) successfully validated the association between Fusobacterium and CRC in a set of matched CRC tumor and normal human colon tissue samples using both pyrosequencing and qPCR analysis of the 16S bacterial rRNA gene. Findings by Mira-Pascual et al. (2015) further confirm this trend, as this group observed a significantly higher presence of $F$. nucleatum in mucosal samples from the CRC patients compared to the healthy subjects (as opposed to matched tissue biopsies). Recent studies have also reported a higher presence of Fusobacterium species in human colonic adenomas (polyps) and in stool samples from adenoma and tumor carcinoma patients compared to healthy subjects (Kostic et al., 2012; 2013; McCoy et al., 2013). Furthermore, other studies have expanded these findings to identify potential mechanisms of action of $F$. nucleatum during tumorigenesis (Rubinstein et al., 2013; Gur et al., 2015). Rubenstein et al. (2013) also indirectly confirm a higher abundance of Fusobacterium in CRC patients by measuring higher F. nucleatum FadA mRNA expression relative to healthy controls.

\section{Materials and methods}

Unless otherwise noted, all protocol information was derived from the original paper, references from the original paper, or information obtained directly from the authors. An asterisk $\left(^{*}\right)$ indicates data or information provided by the Reproducibility Project: Cancer Biology core team. A hashtag (\#) indicates information provided by the replicating lab.

\section{Protocol 1: quantitative PCR for amplification of $F$. nucleatum from matched normal and tumor human colon cancer specimens}

This protocol utilizes quantitative PCR to test the relative abundance of $F$. nucleatum DNA in gDNA isolated from matched normal and tumor human colon cancer specimens. It is a replication of Figure 2.

\section{Sampling}

- This experiment will include 40 matched samples for a final power of $87.26 \%$. - See power calculations for details.

- Each patient sample has two cohorts:

- Cohort 1: Colon tumor sample $(n=40)$

- Cohort 2: Matched normal tissue within the same individual $(n=40)$

- Cohort 3: Age/ethnicity-matched normal tissue from additional control individuals $(n=40)$

- Tissue is collected during surgery (either partial colectomy, ileocolectomy, colorectal resection, or proctocolectomy) from tumor tissue, adjacent normal tissue, or from normal controls. Samples are frozen on liquid nitrogen within $30 \mathrm{~min}$ after extractions. Diagnosis is confirmed by a pathologist using histological sections from each sample.

- Quantitative PCR will be performed for each sample two independent times in technical triplicate for the following: 
- F. nucleatum DNA

- Prostaglandin transporter-reference gene

\section{Materials and reagents}

\begin{tabular}{|c|c|c|c|}
\hline Reagent & Manufacturer & Catalog \# & Comments \\
\hline $\begin{array}{l}\text { Frozen human colon tumor samples } \\
\text { and matched normal samples }\end{array}$ & \#iSpecimen & & $\begin{array}{l}\text { Data include age, gender, ethnicity, } \\
\text { diagnosis, histopathology report }\end{array}$ \\
\hline $\begin{array}{l}\text { Gentra Puregene Genomic } \\
\text { DNA extraction kit }\end{array}$ & Qiagen & 158667 & Replaces Qiagen 69504 \\
\hline PicoGreen Assay & "Life Technologies & P7589 & \\
\hline Spectrophotometer & \#NanoDrop & ND1000 & \\
\hline 384-well optical PCR plate & \#Phoenix Research & MPS-3898 & \\
\hline Fusobacteria forward qPCR primer & \multirow{3}{*}{$\begin{array}{l}\text { Part of a custom-designed } \\
\text { Taqman primer/probe set } \\
\text { (Applied Biosystems) }\end{array}$} & & $\begin{array}{l}\text { CAACCATTACTTTAACTCTA } \\
\text { CCATGTTCA }\end{array}$ \\
\hline Fusobacteria reverse qPCR primer & & & $\begin{array}{l}\text { GTTGACTTTACAGAAGGAGA } \\
\text { TTATGTAAAAATC }\end{array}$ \\
\hline Fusobacteria FAM probe & & & $\begin{array}{l}\text { TCAGCAACTTGTCCTTCTTGA } \\
\text { TCTTTAAATGAACC }^{\dagger}\end{array}$ \\
\hline PGT forward qPCR primer & \multirow{3}{*}{$\begin{array}{l}\text { Part of a custom-designed } \\
\text { Taqman primer/probe set } \\
\text { (Applied Biosystems) }\end{array}$} & & ATCCCCAAAGCACCTGGTTT \\
\hline PGT reverse qPCR primer & & & $\begin{array}{l}\text { AGAGGCCAAGATAGTCCTG } \\
\text { GTAA }\end{array}$ \\
\hline PGT FAM probe & & & ССАТССАТGТССТСАТСТС \\
\hline TaqMan Universal Master Mix & $A B I$ & ${ }^{\#} 4304437$ & \\
\hline qPCR thermal cycling system & $\mathrm{ABI}$ & \#4351405 & $7900 \mathrm{HT}$ system \\
\hline
\end{tabular}

${ }^{\dagger}$ Note: Probe sequence from original manuscript incorrect. Correct sequence seen here from Flanagan et al., 2014

\section{Procedure}

1. Obtain $\sim 40$ sets from frozen human $C R C$ tumors with matched normal control, and an additional control group of age/ethnicity-matched tissue from healthy individuals.

a. Tissue will have been flash-frozen in liquid nitrogen very soon after harvest.

b. Pathological data showing positive diagnosis for CRC will be included with samples.

2. Extract gDNA using Gentra Puregene genomic DNA extraction kit according to manufacturer's instructions.

3. Quantify gDNA concentration by Nanodrop spectrophotometer.

4. Assemble $20 \mu \mathrm{L}$ qPCR reactions in a 384-well optical PCR plate. Each sample is assayed in triplicate for each primer/probe set. Each reaction contains:

a. $5 \mathrm{ng}$ of gDNA

b. $18 \mu \mathrm{M}$ of each primer

c. $5 \mu \mathrm{M}$ of probe

d. $1 \mathrm{X}$ final concentration of TaqMan Universal Master Mix

5. Perform amplification and detection of DNA using the following reaction conditions:
a. 2 min at $50^{\circ} \mathrm{C}$
b. $10 \mathrm{~min}$ at $95^{\circ} \mathrm{C}$
c. 40 cycles of $15 \mathrm{~s}$ at $95^{\circ} \mathrm{C}$ and $1 \mathrm{~min}$ at $60^{\circ} \mathrm{C}$.

6. Calculate cycle threshold using the automated settings. Analyze and compute $\Delta \Delta C_{T}$ values by normalizing to prostaglandin transporter reference gene.

a. The mean $\Delta \Delta C_{\mathrm{T}}$ values from the technical replicates from the tumor and normal sample will be used to calculate the ratio of tumor versus normal for each matched biopsy.

7. Repeat steps 3-5 for each sample a second time. 
a. The mean ratios of $\Delta \Delta C_{\mathrm{T}}$ values in tumor versus normal sample from the two independent experimental replicates will be calculated for each matched biopsy.

\section{Deliverables}

- Data to be collected:

- Descriptive data of gDNA samples including: patient sample age/sex, ethnicity, and \% area of the tumor involved with necrosis.

- Purity $\left(A_{260 / 280}\right.$ and $A_{260 / 230}$ ratios) and concentration of isolated total gDNA from tumor biopsies.

- Raw qRT-PCR values, as well as analyzed $\Delta \Delta C_{T}$ values for each tumor and matched biopsy sample. Bar graph of mean relative abundance of $F$. nucleatum in tumor versus normal colorectal samples (compare to Figure $2 \mathrm{~A}$ ).

\section{Confirmatory analysis plan}

This replication attempt will perform the statistical analysis listed below:

- Statistical analysis of replication data:

- Note: At the time of analysis, we will perform the Shapiro-Wilk test and generate a quantile-quantile $(q-q)$ plot to assess the normality of the data. If the data appear skewed, we will perform the appropriate transformation in order to proceed with the proposed statistical analysis. If this is not possible, we will perform the equivalent nonparametric test (e. g., Wilcoxon-signed rank test).

- One-sample Student's t-test using the log of the mean ratios of $\Delta \Delta C_{T}$ values from the two independent experimental replicates, tumor $\Delta \Delta C_{T} /$ matched within individual controls compared to a mean value of zero.

- Additional exploratory analysis:

- Two Student's t-tests with Bonferroni correction comparing absolute values from:

- Mean tumor Fusobacterium abundance versus within subject matched control (paired)

- Mean tumor Fusobacterium abundance versus healthy matched control (unpaired)

- Meta-analysis of original and replication attempt effect sizes:

- Compute the effect size, compare it against the effect size in the original paper and use a random effects meta-analytic approach to combine the original and replication effects, which will be presented as a forest plot.

\section{Known differences from the original study}

All known differences are listed in the 'Materials and reagents' section with the originally used item listed in the comments section. All differences have the same capabilities as the original and are not expected to alter the experimental design. We have added an additional control of matched gDNA from healthy individuals.

Provisions for quality control

The sample purity $\left(A_{260 / 280}\right.$ and $A_{260 / 230}$ ratios) of the isolated gDNA from each sample will be reported. All of the raw data, including the analysis files, will be uploaded to the project page on the OSF (https://osf.io/v4se2) and made publically available.

\section{Power calculations}

For a detailed breakdown of all power calculations, see spreadsheet at https://osf.io/yadgq/

\section{Protocol 1}

Summary of original data

- Note: Data estimated from graph reported in Figure 2. 


\begin{tabular}{|c|c|c|}
\hline Sample & Log (mean) & $\mathbf{N}$ \\
\hline 1 & 1.5787 & 2 \\
\hline 2 & 1.1957 & 2 \\
\hline 3 & 0.9277 & 2 \\
\hline 4 & 0.8766 & 2 \\
\hline 5 & 0.5192 & 2 \\
\hline 6 & 0.4468 & 2 \\
\hline 7 & 0.4128 & 2 \\
\hline 8 & 0.3149 & 2 \\
\hline 9 & 0.2936 & 2 \\
\hline 10 & 0.2681 & 2 \\
\hline 11 & 0.2766 & 2 \\
\hline 12 & 0.2383 & 2 \\
\hline 13 & 0.234 & 2 \\
\hline 14 & 0.2 & 2 \\
\hline 15 & 0.1787 & 2 \\
\hline 16 & 0.1703 & 2 \\
\hline 17 & 0.1617 & 2 \\
\hline 18 & 0.1362 & 2 \\
\hline 19 & 0.0681 & 2 \\
\hline 20 & 0.0298 & 2 \\
\hline 21 & 0.034 & 2 \\
\hline 22 & 0.0128 & 2 \\
\hline 23 & 0.0095 & 2 \\
\hline 24 & 0.017 & 2 \\
\hline 25 & 0.0213 & 2 \\
\hline 26 & 0.0213 & 2 \\
\hline 27 & 0.0255 & 2 \\
\hline 28 & 0.0128 & 2 \\
\hline 29 & 0.017 & 2 \\
\hline 30 & 0.0128 & 2 \\
\hline 31 & 0.017 & 2 \\
\hline 32 & 0.0255 & 2 \\
\hline 33 & 0.0213 & 2 \\
\hline 34 & 0.0301 & 2 \\
\hline 35 & 0.034 & 2 \\
\hline 36 & 0.0555 & 2 \\
\hline 37 & 0.1362 & 2 \\
\hline 38 & 0.1447 & 2 \\
\hline 39 & 0.1745 & 2 \\
\hline 40 & 0.1915 & 2 \\
\hline 41 & 0.2 & 2 \\
\hline 42 & 0.2086 & 2 \\
\hline
\end{tabular}

Continued on next page 
Continued

\begin{tabular}{|c|c|c|}
\hline Sample & Log (mean) & $\mathbf{N}$ \\
\hline 43 & 0.217 & 2 \\
\hline 44 & 0.2213 & 2 \\
\hline 45 & 0.2596 & 2 \\
\hline 46 & 0.4043 & 2 \\
\hline 47 & 0.4468 & 2 \\
\hline 48 & 0.4511 & 2 \\
\hline 49 & 0.4681 & 2 \\
\hline 50 & 0.4979 & 2 \\
\hline 51 & 0.5064 & 2 \\
\hline 52 & 0.5021 & 2 \\
\hline 53 & 0.549 & 2 \\
\hline 54 & 0.5787 & 2 \\
\hline 55 & 0.5787 & 2 \\
\hline 56 & 0.5872 & 2 \\
\hline 57 & 0.6085 & 2 \\
\hline 58 & 0.6213 & 2 \\
\hline 59 & 0.6553 & 2 \\
\hline 60 & 0.6979 & 2 \\
\hline 61 & 0.7234 & 2 \\
\hline 62 & 0.7617 & 2 \\
\hline 63 & 0.8043 & 2 \\
\hline 64 & 0.8298 & 2 \\
\hline 65 & 0.966 & 2 \\
\hline 66 & 0.9617 & 2 \\
\hline 67 & 1.0042 & 2 \\
\hline 68 & 1.0128 & 2 \\
\hline 69 & 1.017 & 2 \\
\hline 70 & 1.0255 & 2 \\
\hline 71 & 1.0681 & 2 \\
\hline 72 & 1.0596 & 2 \\
\hline 73 & 1.0851 & 2 \\
\hline 74 & 1.1234 & 2 \\
\hline 75 & 1.1958 & 2 \\
\hline 76 & 1.3149 & 2 \\
\hline 77 & 1.3149 & 2 \\
\hline 78 & 1.4085 & 2 \\
\hline 79 & 1.6298 & 2 \\
\hline 80 & 1.7575 & 2 \\
\hline 81 & 1.783 & 2 \\
\hline 82 & 1.8723 & 2 \\
\hline 83 & 1.9404 & 2 \\
\hline 84 & 1.983 & 2 \\
\hline
\end{tabular}

Continued on next page 
Continued

\begin{tabular}{|c|c|c|}
\hline Sample & Log (mean) & $\mathbf{N}$ \\
\hline 85 & 2 & 2 \\
\hline 86 & 2.2553 & 2 \\
\hline 87 & 2.4298 & 2 \\
\hline 88 & 2.4723 & 2 \\
\hline 89 & 2.4723 & 2 \\
\hline 90 & 2.5532 & 2 \\
\hline 91 & 2.6723 & 2 \\
\hline 92 & 2.6893 & 2 \\
\hline 93 & 2.9064 & 2 \\
\hline 94 & 3.0596 & 2 \\
\hline 95 & 3.2425 & 2 \\
\hline 96 & 3.3447 & 2 \\
\hline 97 & 3.5872 & 2 \\
\hline 98 & 3.8 & 2 \\
\hline 99 & 4.261 & 2 \\
\hline
\end{tabular}

\section{Test family}

- Ratio one-sample t-test: $\mathrm{a}_{\text {error }}=0.05, \mu=0$.

\section{Power calculations}

- Ratio t-test and power calculations were performed with R software, version 3.1.2 (Team RC 2014).

\begin{tabular}{lllll}
\hline & Mean & $\begin{array}{l}\text { Effect } \\
\text { size } d\end{array}$ & A priori power & Total sample size \\
\hline Ratio & 0.75893838 & 0.5024568 & $87.26 \%$ & $40^{\star}$ \\
\hline
\end{tabular}

*Forty total ratios (40 tumor 40 matched controls) will be used.

\section{Additional exploratory analysis}

Test family

- Paired Student's t-test (two-tailed): $a_{\text {error }}=0.025$.

Power calculations

- Sensitivity calculations were performed with G*Power software, version 3.1.7 (Faul et al., 2007).

\begin{tabular}{llll}
\hline & & & \\
Group 1 & Group 2 & $\begin{array}{l}\text { Total } \\
\text { size d } \\
\text { sample } \\
\text { size }\end{array}$ \\
\hline Tumor sample & $\begin{array}{l}\text { Adjacent matched } \\
\text { control }\end{array}$ & 0.50384 & A priori power \\
\hline
\end{tabular}


Test family

- Independent Student's t-test (two-tailed): $\mathrm{a}_{\text {error }}=0.025$.

Power calculations

- Sensitivity calculations were performed with G*Power software, version 3.1.7. (Faul et al., 2007).

\begin{tabular}{lllll}
\hline Group 1 & Group 2 & $\begin{array}{l}\text { Detectable effect } \\
\text { size d }\end{array}$ & A priori power & $\begin{array}{l}\text { Total } \\
\text { sample } \\
\text { size }\end{array}$ \\
\hline Tumor sample & $\begin{array}{l}\text { Healthy } \\
\text { individual matched } \\
\text { control }\end{array}$ & 0.7007 & $80 \%$ & 40 \\
\hline
\end{tabular}

\section{Acknowledgements}

The Reproducibility Project: Cancer Biology core team thank Courtney Soderberg at the Center for Open Science for assistance with statistical analyses. We also thank the following companies for generously donating reagents to the Reproducibility Project: Cancer Biology; American Type Culture Collection (ATCC), Applied Biological Materials, BioLegend, Charles River Laboratories, Corning, DDC Medical, EMD Millipore, Harlan Laboratories, LI-COR Biosciences, Mirus Bio, Novus Biologicals, Sigma-Aldrich, and System Biosciences (SBI).

\section{Additional information}

Group author details

Reproducibility Project: Cancer Biology

Elizabeth lorns: Science Exchange, Palo Alto, United States; William Gunn: Mendeley, London, United Kingdom; Fraser Tan: Science Exchange, Palo Alto, United States; Joelle Lomax: Science Exchange, Palo Alto, United States; Nicole Perfito: Science Exchange, Palo Alto, United States; Timothy Errington: Center for Open Science, Charlottesville, United States

\section{Competing interests}

JR: ARQ Genetics is a Science Exchange-associated lab. RP:CB: El, FT, JL, NP: Employed by and hold shares in Science Exchange Inc. The other authors declare that no competing interests exist.

Funding

\section{Funder}

Laura and John Arnold

Foundation

\section{Author}

Reproducibility Project: Cancer Biology

The Reproducibility Project: Cancer Biology is funded by the Laura and John Arnold Foundation, provided to the Center for Open Science in collaboration with Science Exchange. The funder had no role in study design or the decision to submit the work for publication.

Author contributions

JR, NM, KO, Drafting or revising the article; RP:CB, Conception and design; Drafting or revising the article 


\section{References}

Arrieta M-C, Stiemsma LT, Amenyogbe N, Brown EM, Finlay B. 2014. The intestinal microbiome in early life: health and disease. Frontiers in Immunology 5:427. doi: 10.3389/fimmu.2014.00427

Bajzer M, Seeley RJ. 2006. Physiology: obesity and gut flora. Nature 444:1009-1010. doi: 10.1038/4441009a

Brown K, DeCoffe D, Molcan E, Gibson DL. 2012. Diet-induced dysbiosis of the intestinal microbiota and the effects on immunity and disease. Nutrients 4:1095-1119. doi: 10.3390/nu4081095

Båckhed F, Ley RE, Sonnenburg JL, Peterson DA, Gordon JI. 2005. Host-bacterial mutualism in the human intestine. Science 307:1915-1920. doi: 10.1126/science.1104816

Castellarin M, Warren RL, Freeman JD, Dreolini L, Krzywinski M, Strauss J, Barnes R, Watson P, Allen-Vercoe E, Moore RA, Holt RA. 2012. Fusobacterium nucleatum infection is prevalent in human colorectal carcinoma. Genome Research 22:299-306. doi: 10.1101/gr.126516.111

Chen H-M, Yu Y-N, Wang J-L, Lin Y-W, Kong X, Yang C-Q, Yang L, Liu Z-J, Yuan Y-Z, Liu F, Wu J-X, Zhong L, Fang D-C, Zou W, Fang J-Y. 2013. Decreased dietary fiber intake and structural alteration of gut microbiota in patients with advanced colorectal adenoma. American Journal of Clinical Nutrition 97:1044-1052. doi: 10. 3945/ajcn.112.046607

Collins SM. 2014. A role for the gut microbiota in IBS. Nature Reviews Gastroenterology \& Hepatology 11:497505. doi: $10.1038 /$ nrgastro.2014.40

Dulal S, Keku TO. 2014. Gut microbiome and colorectal adenomas. The Cancer Journal 20:225-231. doi: 10. 1097/PPO.0000000000000050

Errington TM, lorns E, Gunn W, Tan FE, Lomax J, Nosek BA. 2014. An open investigation of the reproducibility of cancer biology research. eLife 3:e04333. doi: 10.7554/eLife.04333

Faul F, Erdfelder E, Lang A-G, Buchner A. 2007. G*power 3: a flexible statistical power analysis program for the social, behavioral, and biomedical sciences. Behavior Research Methods 39:175-191. doi: 10.3758/BF03193146

Fearon ER. 2011. Molecular genetics of colorectal cancer. Annual Review of Pathology: Mechanisms of Disease 6:479-507. doi: 10.1146/annurev-pathol-011110-130235

Flanagan L, Schmid J, Ebert M, Soucek P, Kunicka T, Liska V, Bruha J, Neary P, Dezeeuw N, Tommasino M, Jenab M, Prehn JH, Hughes DJ. 2014. Fusobacterium nucleatum associates with stages of colorectal neoplasia development, colorectal cancer and disease outcome. European Journal of Clinical Microbiology \& Infectious Diseases 33:1381-1390. doi: 10.1007/s10096-014-2081-3

Gur C, Ibrahim Y, Isaacson B, Yamin R, Abed J, Gamliel M, Enk J, Bar-On Y, Stanietsky-Kaynan N, CoppenhagenGlazer S, Shussman N, Almogy G, Cuapio A, Hofer E, Mevorach D, Tabib A, Ortenberg R, Markel G, Miklić K, Jonjic S, Brennan CA, Garrett WS, Bachrach G, Mandelboim O. 2015. Binding of the Fap2 protein of fusobacterium nucleatum to human inhibitory receptor TIGIT protects tumors from immune cell attack. Immunity 42:344-355. doi: 10.1016/j.immuni.2015.01.010

Hold GL, Smith M, Grange C, Watt ER, El-Omar EM, Mukhopadhya I. 2014. Role of the gut microbiota in inflammatory bowel disease pathogenesis: what have we learnt in the past 10 years? World Journal of Gastroenterology 20:1192-1210. doi: 10.3748/wjg.v20.i5.1192

Jones ML, Tomaro-Duchesneau C, Prakash S. 2014. The gut microbiome, probiotics, bile acids axis, and human health. Trends in Microbiology 22:306-308. doi: 10.1016/j.tim.2014.04.010

Keku TO, Dulal S, Deveaux A, Jovov B, Han X. 2015. The gastrointestinal microbiota and colorectal cancer. American Journal of Physiology - Gastrointestinal and Liver Physiology 308:G351-G363. doi: 10.1152/ajpgi. 00360.2012

Kostic AD, Chun E, Robertson L, Glickman JN, Gallini CA, Michaud M, Clancy TE, Chung DC, Lochhead P, Hold GL, El-Omar EM, Brenner D, Fuchs CS, Meyerson M, Garrett WS. 2013. Fusobacterium nucleatum potentiates intestinal tumorigenesis and modulates the tumor-immune microenvironment. Cell Host \& Microbe 14:207215. doi: 10.1016/j.chom.2013.07.007

Kostic AD, Gevers D, Pedamallu CS, Michaud M, Duke F, Earl AM, Ojesina Al, Jung J, Bass AJ, Tabernero J, Baselga J, Liu C, Shivdasani RA, Ogino S, Birren BW, Huttenhower C, Garrett WS, Meyerson M. 2012. Genomic analysis identifies association of fusobacterium with colorectal carcinoma. Genome Research 22:292-298. doi: 10.1101/gr.126573.111

Kubota Y. 1990. [Fecal intestinal flora in patients with colon adenoma and colon cancer]. Nihon Shokakibyo Gakkai Zasshi 87:771-779.

Ley RE, Peterson DA, Gordon Jl. 2006. Ecological and evolutionary forces shaping microbial diversity in the human intestine. Cell 124:837-848. doi: 10.1016/j.cell.2006.02.017

McCoy AN, Araújo-Pérez F, Azcárate-Peril A, Yeh JJ, Sandler RS, Keku TO, Goel A. 2013. Fusobacterium is associated with colorectal adenomas. PLoS ONE 8:e53653. doi: 10.1371/journal.pone.0053653

Mira-Pascual L, Cabrera-Rubio R, Ocon S, Costales P, Parra A, Suarez A, Moris F, Rodrigo L, Mira A, Collado MC. 2015. Microbial mucosal colonic shifts associated with the development of colorectal cancer reveal the presence of different bacterial and archaeal biomarkers. Journal of Gastroenterology 50:167-179. doi: 10. 1007/s00535-014-0963-x

Mundade R, Imperiale TF, Prabhu L, Loehrer PJ, Lu T. 2014. Genetic pathways, prevention, and treatment of sporadic colorectal cancer. Oncoscience 1:400-406. doi: 10.18632/oncoscience.59

Nugent JL, McCoy AN, Addamo CJ, Jia W, Sandler RS, Keku TO. 2014. Altered tissue metabolites correlate with microbial dysbiosis in colorectal adenomas. Journal of Proteome Research 13:1921-1929. doi: 10.1021/ pr4009783 
Rodríguez JM, Murphy K, Stanton C, Ross RP, Kober OI, Juge N, Avershina E, Rudi K, Narbad A, Jenmalm MC, Marchesi JR, Collado MC. 2015. The composition of the gut microbiota throughout life, with an emphasis on early life. Microbial Ecology in Health \& Disease 26:26050. doi: 10.3402/mehd.v26.26050

Rubinstein MR, Wang X, Liu W, Hao Y, Cai G, Han YW. 2013. Fusobacterium nucleatum promotes colorectal carcinogenesis by modulating e-cadherin/-catenin signaling via its FadA adhesinn. Cell Host \& Microbe 14:195206. doi: 10.1016/j.chom.2013.07.012

Tahara T, Yamamoto E, Suzuki H, Maruyama R, Chung W, Garriga J, Jelinek J, Yamano H.-o., Sugai T, An B, Shureiqi I, Toyota M, Kondo Y, Estecio MRH, Issa J-PJ. 2014. Fusobacterium in colonic flora and molecular features of colorectal carcinoma. Cancer Research 74:1311-1318. doi: 10.1158/0008-5472.CAN-13-1865

Team RC. 2014. R: a language and environment for statistical computing . R Foundation for Statistical Computing Vienna, Austria.

Vogelstein B, Fearon ER, Hamilton SR, Kern SE, Preisinger AC, Leppert M, Nakamura Y, White R, Smits AM, Bos JL. 1988. Genetic alterations during colorectal-tumor development. New England Journal of Medicine 319: 525-532. doi: 10.1056/NEJM198809013190901

Warren RL, Freeman DJ, Pleasance S, Watson P, Moore RA, Cochrane K, Allen-Vercoe E, Holt RA. 2013. Cooccurrence of anaerobic bacteria in colorectal carcinomas. Microbiome 1:16. doi: 10.1186/2049-2618-1-16 